\title{
Improving outcomes in diabetic foot surgery after the implementation of measures for diagnosis and treatment
}

\author{
V. Crihana
}

Corresponding author:

Viorel Crihana, MD Surgeon

Department of General Surgery, llfov

County Hospital, Bucharest, Romania

E-mail:viorel_crihana@yahoo.com
Department of General Surgery, Ilfov County Hospital, Bucharest, Romania

\section{ABSTRACT}

Diabetes is considered a worldwide health problem, and diabetic foot ulcers are considered important complications of this disease. Evaluation of treatment outcomes of operated neuropathic diabetic foot, following major amputation rate, number of days of hospitalization and postoperative complications. In this study we compared a control group (retrospective) from 2007-2010, consisting of 124 patients with neuropathic diabetic foot and a group of 106 patients, analyzed over a period of 3 years (2011-2013), after the implementation of a multidisciplinary diagnosis and treatment program of patients with lesions classified by the Wagner classification as - 1,2,3,4,5 lessions. After implementation of these measures for diagnosis and treatment in the study group we were able to decrease the rate of major amputation (neuropathic forms) from $10.48 \%$ (control group), to 2,83 \% (the study group) also average length of stay was decreased from 11 days (control group) to 9 days. Postoperative complications decreased significantly in the study group. Therefore, implementation of complex diagnosis and treatment teams for lesions of diabetic foot insure a significant decrease of postoperative complications, major amputation rate and reduced length of stay.

Key words: diabetic foot ulcer, International Consensus on the Diabetic Foot, amputation

\section{INTRODUCTION}

Diabetes is considered a worldwide health problem, and diabetic foot ulcers are considered important complications of this disease. It is estimated, that worldwide, there are about 171 million diabetic patients and this number will double in 2030. $(1,2,3)$

In this study patients present a very high risk of diabetic foot ulcers, furthermore it has been reported that the annual incidence is about $1 \%$ to $4 \%(1,3)$ worldwide, with a prevalence of $4-10 \% .(4,5)$ Patients with diabetes reach major or minor amputations in lower limbs in 15 to $27 \%$. $(6,7,2)$ Major amputations are associated with an increased risk of morbidity and mortality ( $13 \%$ to $40 \%$ at one year and $39-80 \%$ at 5 years). $(8,9)$ 
In this study we aim to investigate the possibility of decreasing the rate of postoperative complications and major amputations by implementing of specific measures for diagnosis and multidisciplinary treatment. We compared the results from two groups of patients one of them analyzed retrospective (124 patients operated in our service between Jan 2007- Dec 2010) and other which was analyzed prospectively, after implementation of International Consensus on the Diabetic Foot measures (106 patients operated between Jan 2011- Dec 2013).

\section{MATERIAL AND METHODS OF RESEARCH}

The study group consisting of 106 patients (group A) with diabetic foot ulcers, was followed from two general surgery wards, with multidisciplinary monitoring (surgeon, diabetologist, anesthesiologist, neurologist, specialist in orthopedic footwear) and the methods of diagnosis and treatment followed a set of rules set out below.

The comparison was performed by retrospective study, a number of 124 patients (control group, group B) studied from a period prior to the implementation of this set of rules.

Framing neuropathic diabetic foot shape was made according to the following criteria:

Assessment of vascular bed:

- Pulse present at level of Pedi artery and posterior tibial artery;

- Ankle-arm presure index greater than 0.8;

- Color Doppler ultrasound excludes vascular pathology $(1,2)$.

Rating neuropathy:

- Evaluation of motor reflex at Achilles tendon;

- Determination of vibration perception in the malleolus;

- Evaluation of tactile sensitivity with a $10 \mathrm{~g}$ monofilament in nine areas of the foot $(1,2)$.

During hospitalization patients were monitored by the diabetologist, patients with type 2 diabetes were switched to insulin treatment, in 3-4 divided doses, monitoring blood glucose levels at least two times a day.

Biological evaluation is common with other surgical interventions, in addition a complex metabolic assessment is made, if there are any imbalances, followed by hydro and acid-base balance.

A very important role is that of clinical and laboratory examination, the classification of each type of lesion is made after Wagner (table 1) (9). Every lession is graded as 1,2,3,4,5.
Table 1

\begin{tabular}{cl}
\hline Grad & Type of lesion \\
\hline 0 & Intact skin, foot deformities present \\
1 & $\begin{array}{l}\text { Shallow ulcers that do not penetrate the subcutaneous } \\
\text { tissues }\end{array}$ \\
2 & $\begin{array}{l}\text { Ulcers that evolves in depth, looking tendons, ligaments, } \\
\text { joint capsules }\end{array}$ \\
3 & $\begin{array}{l}\text { Deep ulcer with osteomyelitis, polyarthritis, abscesses } \\
\text { planting }\end{array}$ \\
4 & Gangrene limited to the fingers \\
\hline 5 & Foot gangrene
\end{tabular}

Radiography of the foot, in two incidents may reveal changes and bone deformities characteristic of Charcot foot, osteitic lesions are seen by Rx if they are staged as bone attachement. For highlighting early osteitic lesions, an important role is that of MRI $(1,4)$.

In the case of infected lessions, antibiotic treatment was started according to the type of lesion, the result of antibiotic sensitivity testing canlead to the change of antibiotic theraphy if necessary. DST showed sensitivity to cephalosporins and quinolones (ciprofloxacin, norfloxacin) about $92 \%$ of cases; lower sensitivity to aminoglycosides (gentamicin) $-59 \%$ and $42 \%$, semisynthetic penicillins. $(1,7)$

Treatment of diabetic neuropathy was done by administrating of drugs such as Milgamma and Thiogamma.

\section{Surgical treatment in neuropathic forms}

Surgery of neuropathic forms (representing 35.56\% of cases) was performed in the immediate emergency for severe forms of infection (phlegmon, extensive necrosis, wet gangrene), in delayed emergency (ulcers of the fingers, fistulising osteitis, perforanting plantar mal) by the need to improve metabolic imbalances, or scheduled operations, especially in reconstructive operations.

The table below (table 2) presentes the types of surgical interventions performed in 106 cases of neuropathic form - study group, 124 cases - control group.

Transfalangian amputation of fingers $(22.64 \%)$ was performed for distal or medium phalanx osteomyelitis, interphalangeal osteoarthritis, gangrene of distal phalanx or deep ulceration with destruction of distal phalanx. In these cases there is the possibility of finger amputation with disarticulation of metatarsophalangeal joint with cartilage resection and removal of sesamoid bones, depending on the extent of the lesion.

Finger amputation associated with metatarsal head resection, with open wound (19.81\%) was performed in 
Table 2

\begin{tabular}{|c|c|c|}
\hline Type of surgical intervention & $\begin{array}{l}\text { Neuropathic form } \\
\text { (Study group) }\end{array}$ & $\begin{array}{l}\text { Neuropathic form } \\
\text { (Control group) }\end{array}$ \\
\hline Finger amputation at level of proximal phalanx with primary wound suture & $24(22,64 \%)$ & $9(7,26 \%)$ \\
\hline Finger amputation at level of proximal phalanx with open stump & $0(0 \%)$ & $15(12,09 \%)$ \\
\hline Finger amputation + Metatarsal head resection + suture of wound & $12(11,32 \%)$ & $9(7,26 \%)$ \\
\hline Finger amputation + Metatarsal head resection + open wound & $21(19,81 \%)$ & $31(25,00 \%)$ \\
\hline Joint resection & $2(1,89 \%)$ & $2(1,61 \%)$ \\
\hline Finger amputation + Metatarsal head resection + phlegmon drainage & $8(7,55 \%)$ & $18(14,52 \%)$ \\
\hline Transmetatarsal foot resection & $4(3,77 \%)$ & $9(7,26 \%)$ \\
\hline Necrectomy & $14(13,21 \%)$ & $9(7,26 \%)$ \\
\hline Phlegmon drainage & $18(16,98 \%)$ & $9(7,26 \%)$ \\
\hline Leg Amputation & $3(2,83 \%)$ & $13(10,48 \%)$ \\
\hline Thigh Amputation & $0(0 \%)$ & $0(0 \%)$ \\
\hline Total & $106(100 \%)$ & $124(100 \%)$ \\
\hline
\end{tabular}

the case of wet gangrene comprising the hole finger, proximal phalangian osteitis, interphalangeal or metatarsophalangeal osteoarthritis with finger cellulite. The wound remains open until the disappearance of cellulite, granulation process begins and after that the wound can be closed (secondary suture) through the closing of skin flaps or using skin plasty with flaps from the front and lateral plantar of amputated finger.

Finger amputation with metatarsal head resection associated with wound suture (11.32\%) was carried out for osteitis or fistulising osteoarthritis, dry gangrene, stretched ulcers, where surgery completely removed infected tissue and cellulite was missing. Given the

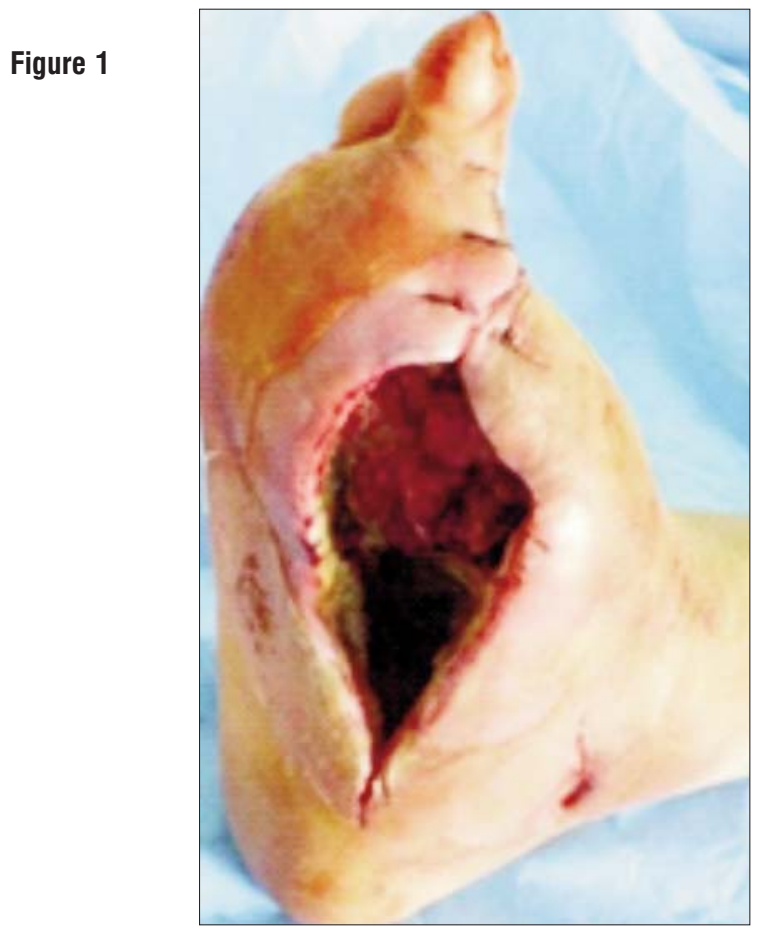

importance of fingers I and $\mathrm{V}$ (in gait biomechanics) is best that they are salvaged. Metatarsal bone stump was resected, rounded to prevent sharp edges in areas of plantar support.

Lesions located at finger level (wet gangrene, phalangial osteitis, osteoarthritis) may be associated with proximal efusion of infectious process with the presence of plantar or dorsal phlegmon. In this case, beside finger amputation, it is required to perform incisions at plantar or dorsal level in order to drain the pus and for the debridement of necrotic tissue $(7,55 \%)$ - figure 1 .

Neuropathic plantar ulcers (soles perforating malus), most commonly localised in the projection of the metatarsal bone or bone protuberosis without bone infliction (osteitis, osteoarthritis) are treated by excision of thickened tissue with or without skin suture (figure 2, $A$ and $B$ ).

If these plantar ulcers are associated with metatarsophalangeal osteoarthritis or with major joint deformities witch create extensive plantar pressure at this level, you can perform, besides excision of perforating malus, joint resection (1.89\%), including bone ends that participate in joint training, maintaining aesthetics. The patient continues antibiotic treatment and remains in bed for 5 days, then can use special orthotics in order to discharge pressure. If there is concomitant osteoarthritis, interesting multiple metatarsophalangeal joints II , III, IV, the incision may be transverse on the dorsal foot, with excision of involved joints and necrotic tissue, with suture and drainage.

If irreversible lesions, which comprise all the forefoot (wet gangrene, osteitis, osteoarthritis of the fingers and metatarsal bones) and in the case of extended lesions to the remnant fingers, trans-metatarsal amputation of foot is carried out (3 77\%), or disjointing of tarso- 

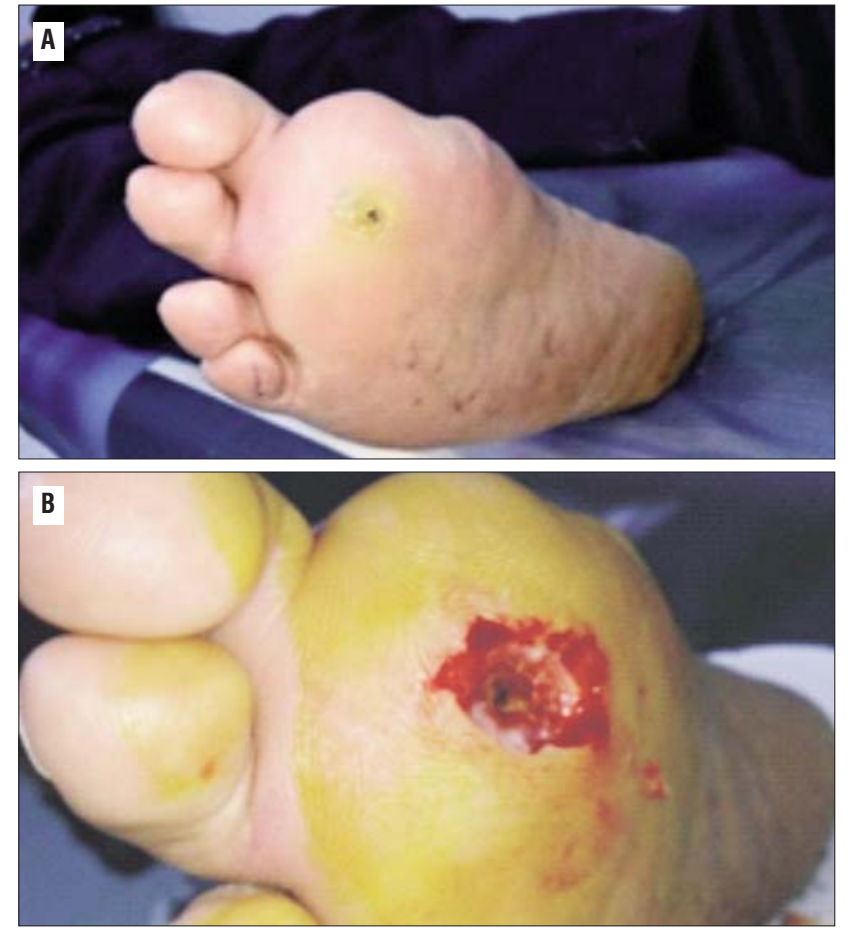

Figure 2 - Soles perforating malus (projection of the head of metatarsal bone II) - A. Preop B. Postop

metatarsal joints and even inter-tarsal resections (where osteitis lies at tarsal bones) figure 3. Transverse incision is performed on the dorsum of the foot, in the middle third of the metatarsal shaft with their sectioning, about $1 \mathrm{~cm}$ proximal to the skin, leaving the plantar flap longer (in case of a good blood supply) to cover the bone stumps.

The wound is sutured with rare sutures tightened moderately not to be ischemic, drainage is performed with perforated silicone tubing (figure 3 ).

In case of phlegmon of the foot, depending on the location of the infectious process, basic surgical treatment consist in debridement of the infected area and necrotic tissue( $16.98 \%$ ) , according to the following principles:

- Extensive dissection and opening of the purulent focus according to location and the possibility of obtaining well vascularized flaps used for subsequent plasty of wound defect;

- Excision of necrotic tissue, removal of necrotic bone sequesters from the wound;

- Adequate hemostasis and wound drainage $(3,5)$.

One of the compulsory in the postoperative period for all patients, was major limitation of exercise on the affected leg to prevent relapse of trophic ulcer by orthopedic footwear.

The final stage of treatment for neuropathic diabetic

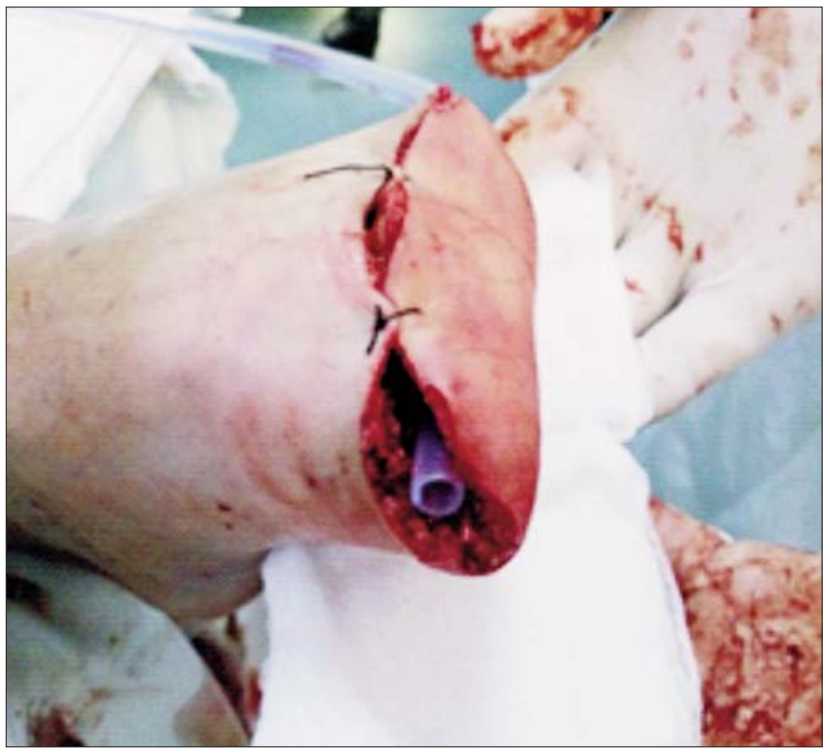

Figure 3

foot, infected or not, is plastic surgery performed in order to close the defect. Conditions needed for undergoing these plastic surgeries were: improvement of general status of the patient, sufficient soft tissue vascularization of the affected limb, solving infectious process ( 8 ). In the majority of cases plastic surgery ends with the complete closure of the defect. Prevention of possible complications, resulting from the study, lies in the proper rehabilitation of the plant or stump planting. For this purpose early reconstructive plastic surgery were made. Depending on the form, size and location of the wound defect the following plastic surgeries were performed:

- Wound plasty using split skin flap;

- Wound plasty with local tissues or plasty using soft tissues flap from the fingers.

Statistical study of these two groups: study group (group A), control group (group B) include information on sex, age, lesion type (classified as Wagner classification), postoperative complications, length of hospitalization, major amputation rate.

In both groups predominate male patients, $73.58 \%$ and $78.22 \%$ (table 3 ).

Age of patients in the two groups was between 30 and 80 years, the number of cases between 50 and 60 years, median 55 (group A) and 57 (group B) (table 4, figure 4).

Diabetic foot lesions appeared generally after 5 years of evolution of diabetes with a maximum between 10 and 15 years (table 5, figure 5). 
Table 3

\begin{tabular}{lccc}
\hline Variabile & Group A & Group B & $\begin{array}{c}\text { p value } \\
\text { [CI95\%] difference }\end{array}$ \\
\hline Sex M - Nr (\%) & $78 / 106(73.58)$ & $97 / 124(78.22)$ & $0.4108^{1}$ \\
\hline Sex F $-\mathrm{Nr}(\%)$ & $28 / 106(26.42)$ & $27 / 124(21.78)$ & - \\
\hline Two-sample $\chi^{2}$ test two-sided for proportion & &
\end{tabular}

Table 4

$\left.\begin{array}{lcc}\hline \text { Age } & \text { Group A (Study) } & \text { Group B (Control) } \\ \hline \text { Mean [Cl95\%] } & \begin{array}{c}55.83 \\ \text { [from } 54.13 \text { to } 57.50]\end{array} & 57.40 \\ \text { [from } 55.63 \text { to } 59.17]\end{array}\right]$
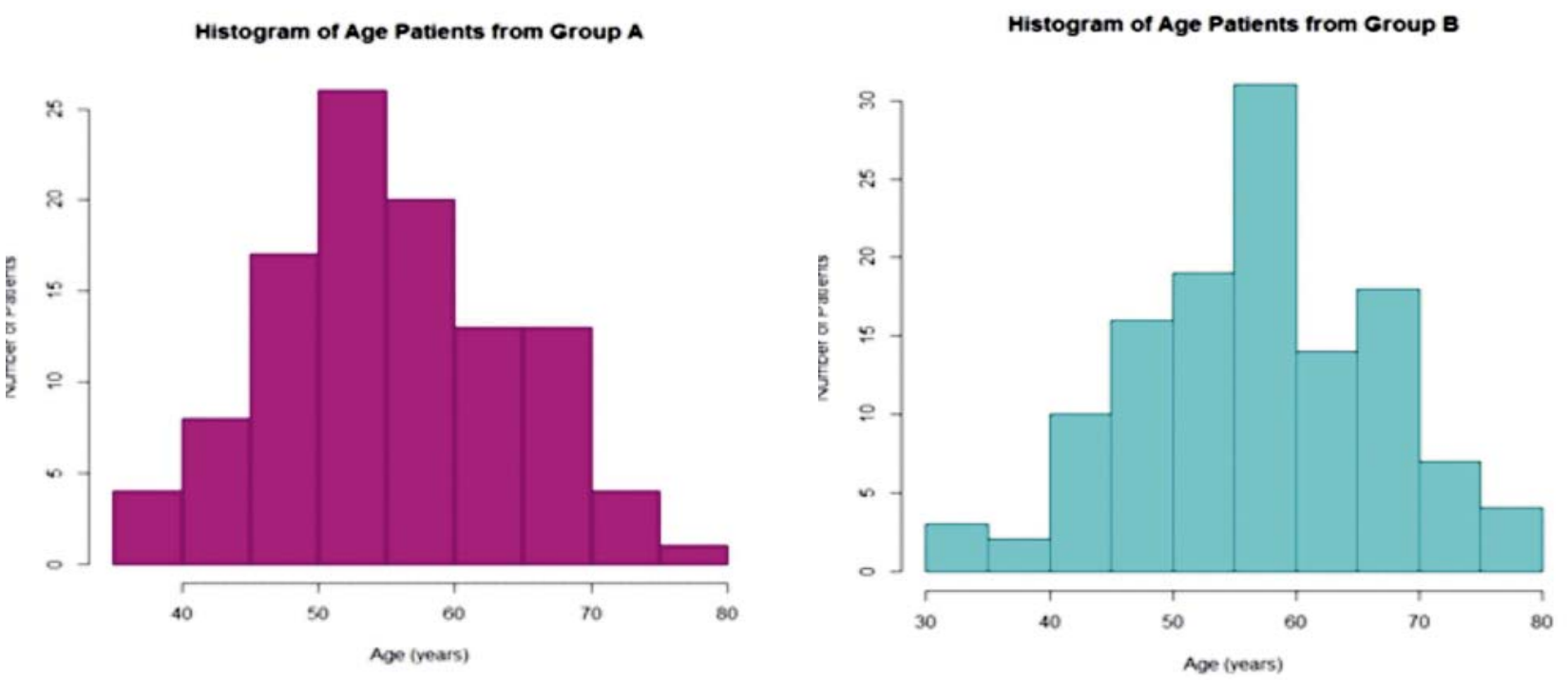

Figure 4 - Age Difference Two-sample Welch $\mathrm{t}$ test two-sided

\begin{tabular}{lcccc}
\hline T statistics & Degrees of freedom & Mean difference & P Value & CI95\% for difference \\
\hline-1.2814 & 227.834 & -1.57 & 0.2014 & -4.01 to 0.85 \\
\hline
\end{tabular}

Because $p$ is $>0.05$ and Cl95\% contains 0 , there is no semnificative difference between groups.

Table 5

\begin{tabular}{|c|c|c|}
\hline Diabetes History & Group A (Study) n = 106 & Group B (Control) $n=124$ \\
\hline Mean [CI95\%] & 10.23 [9.33 to 11.13$]$ & $10.83[10.00$ to 11.65$]$ \\
\hline SD (Variance) & $4.67(21.82)$ & $4.64(21.57)$ \\
\hline Median (IQR) & $10.50(6)$ & $11(6)$ \\
\hline Skewness & 0.41 & 0.08 \\
\hline Kurtosis & 2.37 & 2.62 \\
\hline
\end{tabular}


Diabetes History Difference Two-sample Welch t test two-sided

\begin{tabular}{lcccc}
\hline T statistics & Degrees of freedom & Mean difference & P Value & CI95\% for difference \\
\hline-0.9651 & 222.072 & -0.60 & 0.3355 & -1.80 to 0.61 \\
\hline
\end{tabular}

Because $\mathrm{p}$ is $>0.05$ and $\mathrm{Cl95 \%}$ contains 0, there is no semnificative difference between groups
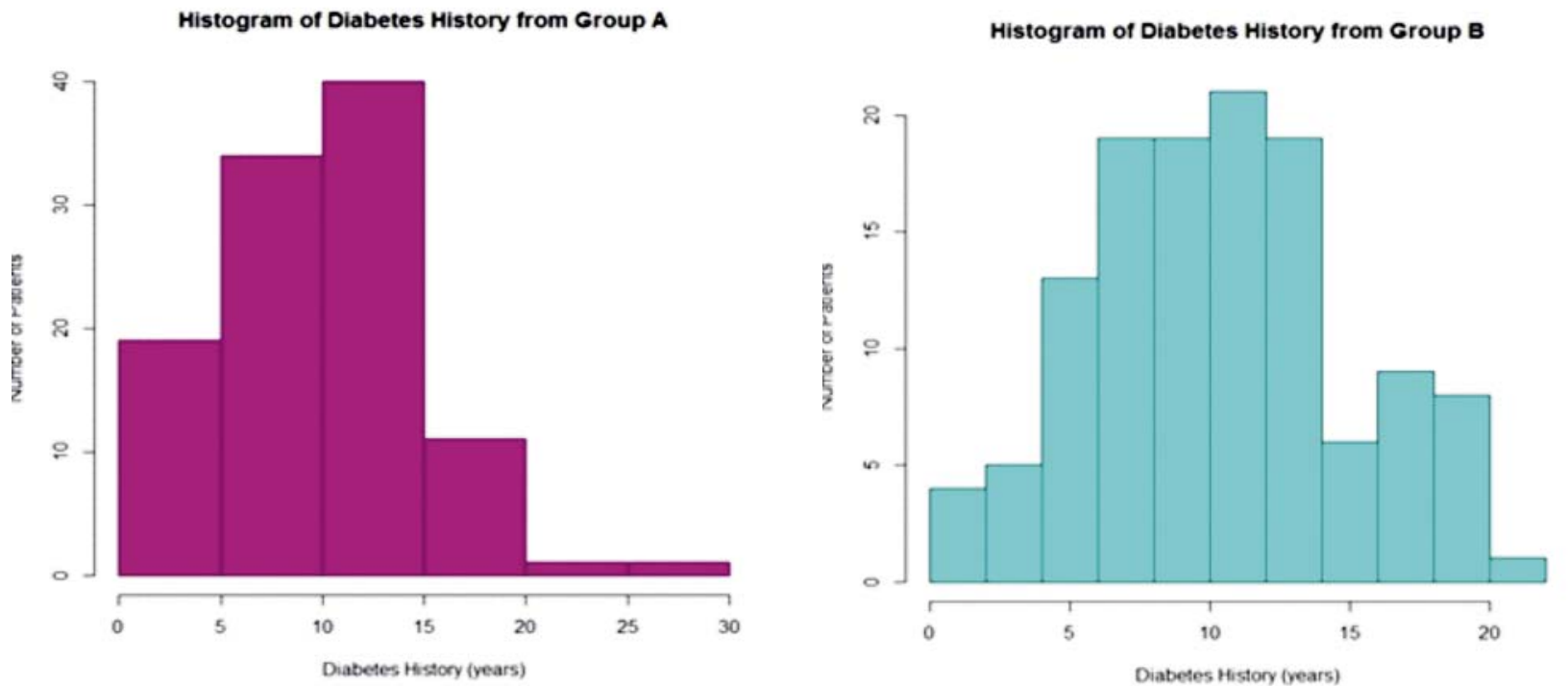

Figure 5

According to Wagner classification, grade 2 lesions were more frequent in both groups (deep ulcers affecting the tendons, muscle, joint capsule), followed by grades 3 and 4 (table 6, figure 6).

\section{RESULTS}

From both groups emerged a number of complications after surgical intervention, depending on the type of surgery performed, according to the type of lesion, which led to an increase in the number of days of hospitalization or repeated hospitalizations, surgical reinterventions possibly with additional minor amputations even major.

Complication rates are shown in comparison in the two groups of patients, in the table below (table 7), finding a significant decrease in the studied group.

Analyzing the length of hospitalization, there was an

Table 6 - Wagner Grade

\begin{tabular}{|c|c|c|}
\hline Wagner Grade & Group A (Study) & Group B (Control) \\
\hline Mean [CI95\%] & 3.01 [2.73 to 3.28$]$ & 2.68 [2.46 to 2.89$]$ \\
\hline SD. (Variance) & $1.44(2.08)$ & $1.20(1.45)$ \\
\hline Median (IQR) & $3(2)$ & $3(2)$ \\
\hline Skewness & -0.14 & -0.42 \\
\hline Kurtosis & 2.18 & 2.83 \\
\hline
\end{tabular}

\begin{tabular}{lcccc}
\hline T statistics & Degrees of freedom & Mean difference & P Value & CI95\% for difference \\
\hline-1.1768 & 205.26 & -0.21 & 0.2406 & 2.95 to 3.16 \\
\hline
\end{tabular}

Because $\mathrm{p}$ is $>0.05$ and $\mathrm{Cl} 95 \%$ contains 0 , there is no semnificative difference between groups 

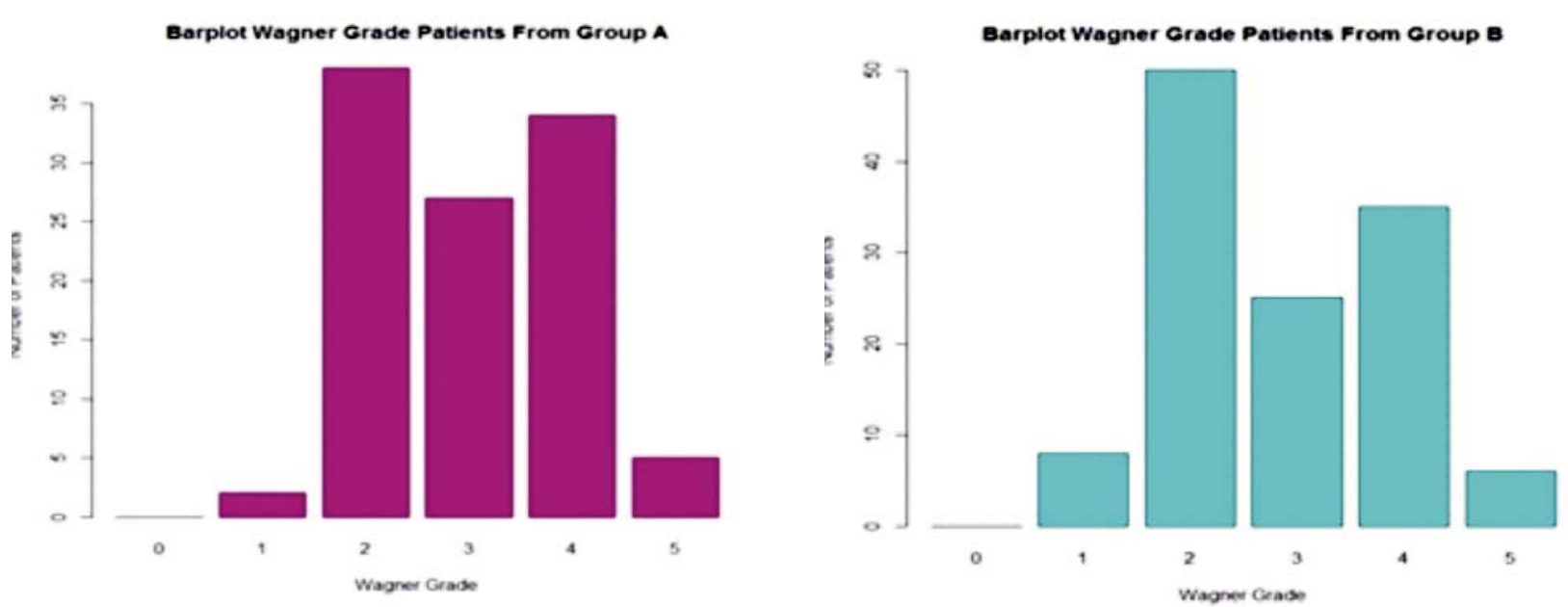

Figure 6

Table 7

\begin{tabular}{|c|c|c|c|c|}
\hline \multirow{2}{*}{$\frac{\text { Postoperative complication }}{\text { (no of operated patients) }}$} & \multicolumn{2}{|c|}{ Neuropathic form - Control group } & \multicolumn{2}{|c|}{ Neuropathic form - Study group } \\
\hline & no. & $\%$ & no. & $\%$ \\
\hline Infected wound after amputation of finger & 9(out of 82 ) & $10,97 \%$ & 5 (out of 65 ) & $7,69 \%$ \\
\hline Infected wound after amputation of finger + gangrene of other finger & 12 (out of 82 ) & $14,13 \%$ & 2 (out of 65 ) & $3,08 \%$ \\
\hline Infected wound after amputation of finger + plantar flegmon & 8 (out of 64 ) & $12,50 \%$ & 1 (out of 65 ) & $1,54 \%$ \\
\hline Infected wound after trans-metatarsal amputation & 2(out of 9 ) & $22,22 \%$ & 0 (out of 4) & $0 \%$ \\
\hline Stump suppuration after leg amputation $+/$ - osteitis & 3 (out of 13) & $23,07 \%$ & 0 (out of 3 ) & $0 \%$ \\
\hline Stump suppuration after thigh amputation $+/$ - osteitis & - & - & -2 & - \\
\hline Tarsal osteitis after operated plantar phlegmon & 3 (out of 27) & $11,11 \%$ & 1 (out of 25$)$ & $4,0 \%$ \\
\hline Extensive necrotizing fasciitis & 3 (out of 124$)$ & $2,41 \%$ & 1 (out of 106) & $0,94 \%$ \\
\hline
\end{tabular}

average of 11 days in the control group compared to 9 days in the study group, finding a decrease in average length of stay (table 8, figure 7).

Following implementation of the program of diagnosis and treatment, there was a decrease in the number of major amputations from $10.48 \%$ to $2.83 \%$ (table 9).

Because $\mathrm{p}$ is $<0.05$ and $\mathrm{Cl} 95 \%$ for risk difference

Tabel 8 - Hospital Stay

\begin{tabular}{|c|c|c|}
\hline Hospital Stay & Group A (Study) & Group B (Control) \\
\hline Mean [Cl95\%] & 9.42 [8.68 to 10.16$]$ & 11.60 [10.71 to 12.49$]$ \\
\hline SD (Variance) & $3.84(14.81)$ & $5.01(25.11)$ \\
\hline Median (IQR) & $9(5.75)$ & $12(8)$ \\
\hline Skewness & 0.47 & 0.08 \\
\hline Kurtosis & 2.91 & 1.88 \\
\hline
\end{tabular}

\begin{tabular}{lcccc}
\hline T statistics & Degrees of freedom & Mean difference & P Value & C195\% for difference \\
\hline-3.7263 & 225.525 & -2.18 & 0.0002 & -3.33 to -1.02 \\
\hline
\end{tabular}

Because $\mathrm{p}$ is $<0.05$ and $\mathrm{Cl95 \%}$ does not contain 0 , there is a semnificative difference between groups duration of hospital stay for patients from study group is less than duration of hospital stay for patients from control group. 

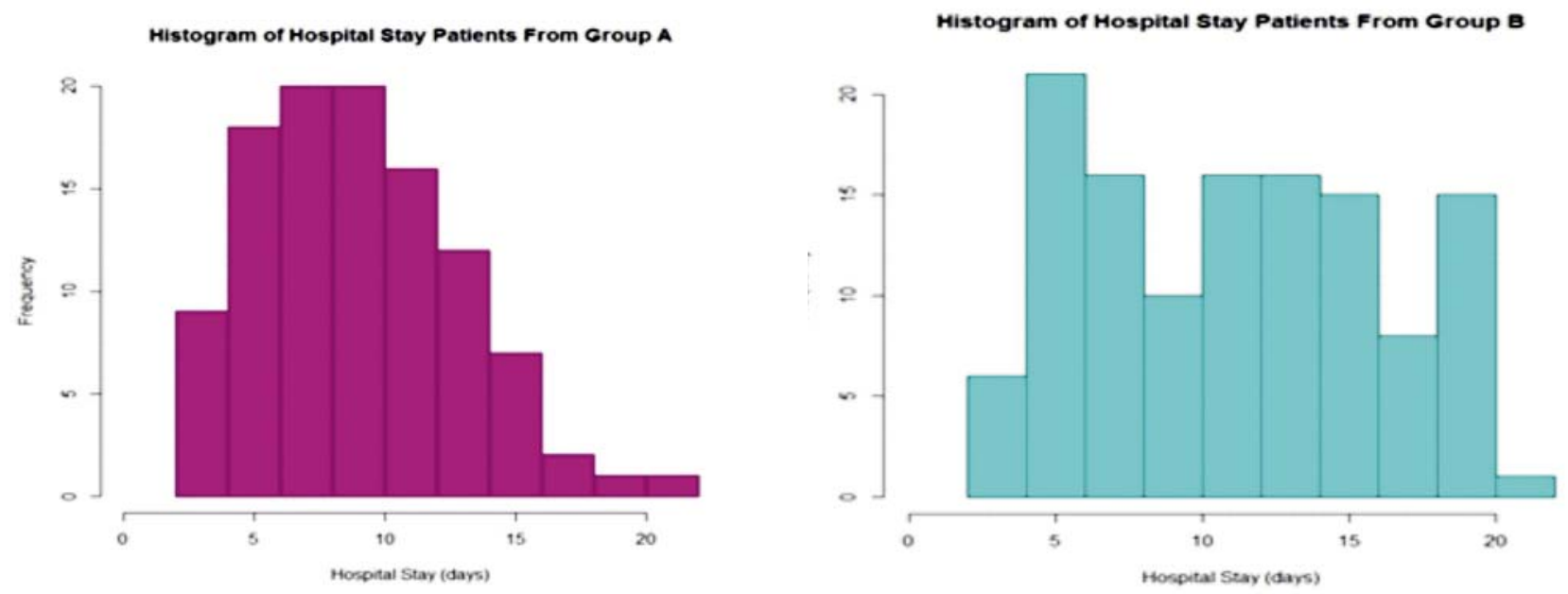

Figure 7

Table 9 - Major Amputations

\begin{tabular}{lcccc}
\hline Group A & Group B & $\begin{array}{c}\text { p Value Fisher's } \\
\text { Exact Test }\end{array}$ & $\begin{array}{c}\text { Risk } \\
\text { Difference [C195\%] }\end{array}$ & $\begin{array}{c}\text { Risk Ratio } \\
\text { [CI95\%] }\end{array}$ \\
\hline $3 / 106(2.83 \%)$ & $13 / 124(10.48 \%)$ & 0.035 & $-7.65 \%$ & 0.26 \\
& & & {$[-13.90 \%$ to $-1.40 \%]$} & {$[0.07$ to 0.92$]$} \\
\hline
\end{tabular}

does not contains 0 and $\mathrm{Cl95 \%}$ for risk ratio does not contain 1 there is a semnificative difference between groups, patients from group A (study group) suffered less major amputations than patient patients from group B (control group)

\section{CONCLUSIONS}

Implementation of this complex diagnosis and treatment programe, involving multidisciplinary teams, with surgical treatment according to the type of lesion, after a correct diagnosis of anatomoclinical form, later complemented by wearing orthopedic shoes, causing a discharge of pressure in the diabetic foot, have led to significant decrease of postoperative complications, major amputation rate and reduced length of stay, if the diabetic foot is operated.

\section{REFERENCES}

1. Current concepts in the surgical management of acute diabetic foot infections .Javier La Fontainea,Kavita Bhavanb, Talal K. Talal, Lawrence A.
Laverya. The Foot 24 (2014) 123-127.

2. Improvement of diabetic foot care after the Implementation of the International Consensus on the Diabetic Foot (ICDF): Results of a 5-year prospective study Roberto Anichini, Franco Zecchini, Ivano Cerretini , Giuseppe Meucci, Daniela Fusilli, Lorenzo Alviggi, Giuseppe Seghieri, Alessandra De Belli. Diabetes Research and Clinical Practice 75 (2007) 153-158

3. Diabetic foot and foot debridement technique.Soroush Sohrabi,David Russell. Surgery - Oxford International Edition,Volume 32,Issue 9Pages 491-495, September 2014

4. Kapoor A, DT. Magnetic resonance imag-ing for diagnosing foot osteomyelitis: a meta-analysis. Arch Intern Med2007;167(2):125-32, http Page S, Lavalley M, Gale DR, Felson. PubMedPMID: 17242312.

5. The Role of Early Surgical Debridement and Revascularization in Patients With Diabetes and Deep Foot Space Abscess: Retrospective Review of 106 Patients With Diabetes Ezio Faglia, , Giacomo Clerici, Maurizio Caminiti, Antonella Quarantiello, Michela Gino, and Alberto Morabito. The journal of foot \& ankle surgery-volume 45, number 4, july/august 2006.

6. R Core Team (2014). R: A language and environment for statistical computing. R Foundation for Statistical Computing, Vienna, Austria.URL http://www.R-project.org/.

7. Michael E Edmonds \& Alethea VM Foster Managing the Diabetic Foot second edition,pg.102-110

8. A systematic approach to the failed plastic surgical reconstruction of the diabetic foot. Ioannis I. Ignatiadis, Vassiliki A. Tsiampa, and Apostolos E. Papalois. Diabetic Foot \& Ankle 2011, 2: 6435

9. A new classification of diabetic foot complications: A simple and effective teaching tool.Authors: Dr Amit Kumar C Jain The Journal of Diabetic Foot Complications, 2012; Volume 4, Issue 1, No. 1, Pages 1-5. 